\title{
ПРИМЕНЕНИЕ ТЕОРИИ ЧЕЛОВЕЧЕСКОГО КАПИТАЛА К РЕШЕНИЮ ПРОБЛЕМ ЭКОНОМИЧЕСКОГО РАЗВИТИЯ И ДЕМОГРАФИИ
}

\author{
А.М. БОНДАРЕВА \\ зав. кафедрой экономической теории, канд. экон. наук, доцент \\ Гомельский государственный технический университет имени П.О.Сухого, г. Гомель, \\ Беларусь, ambon_am@mail.ru
}

\begin{abstract}
Аннотация
В статье прослежен генезис теории человеческого капитала. Классифицировань характеристики человеческого капитала как сущчноти. Определены формы инвестиций в человеческий капитал. Анализируются положения теории человеческого капитала применительно к особенностям экономики Республики Беларусь. Даются рекомендации по использованию закономерностей, выявленных теорией человеческого капитала для решения проблем экономического развития и демографии.

Ключевые слова: человеческий капитал, запасовые и потоковые величины человеческого капитала, инвестиции в человеческий капитал, норма окупаемости человеческого капитала, деформация принципа оплаты труда, самообразование, возможность трудоустройства, нарушаемая тенденция, высокая степень управляемости.
\end{abstract}

Abstract

The genesis of human capital theory is traced back in the article. Characteristics of human capital as an entity are classified and types of human capital investment are defined by the author. The application of the human capital theory to the particular qualities of the Belarusian economy is also analyzed. In the conclusion the author provides the recommendations on the use of regularities identified by human capital theory, in order to find solutions for demographic problems and economic development issues.

\section{ВВЕДЕНИЕ}

Современная экономическая теория трактует человеческий капитал как важнейший элемент национального богатства: с изменением величин показателей, его оценивающих, изменяются показатели национального богатства. Для осмысления тенденций развития современной белорусской экономики необходимо изучение факторов формирования и развития человеческого капитала.

Большинство исследователей придерживается условной периодизации генезиса теории человеческого капитала, содержащей три больших этапа, соответствующих этапам развития производительных сил общества. Для первого периода характерны структурные изменения в 
совокупной рабочей силе и проявление интереса исследователей к факторам экономического роста и экономической динамики в целом. Истоки теории человеческого капитала обнаруживаются в работах У. Петти, А. Смита, К. Маркса, А. Маршалла (17-20 вв.). Для второго периода характерны дальнейшая капитализация отношений и возникновение новых направлений и школ экономической мысли. Отличительные черты его - широкий спектр научных взглядов на природу человека и его производительных способностей. Открытием данного периода является представление о человеке и его способностях как о специфической форме капитала. Следует отметить глубину и подробность работ данного периода. Среди представителей второго периода выделяют И. Фишера, Л. Вальраса, И. Тюнена, Дж. С. Миля (19-20вв.). Третий период (20-21вв.) характеризуется таким развитием постиндустриального общества, что «...Личность выступает как самоцель общечеловеческого развития....является главным орудием прогресса». [1] Постиндустриальному обществу, формирующемуся на этом третьем этапе соответствует своя форма социальности - свободная индивидуальность. Само развитие экономики создало предпосылки для формирования концепции человеческого капитала не только как элемента национального богатства, но и «элемента мировой цивилизации». [2] Основные положения современной теории человеческого капитала сформулированы в трудах Г. Беккера и Т.Шульца.

\section{РЕЗУЛЬТАТЫ И ИХ ОБСУЖДЕНИЕ}

Идеи о сущности человеческого капитала имеют давние истоки в мировой экономической мысли. Одна из первых ее формулировок дана в «Политической арифметике» сэра У. Петти, родоначальника статистики и предшественника классицизма в политической экономии, написанной в 1661 - 1676 г.г. и изданной в 1690 году. Этот знаменитый английский экономист оценил человеческий капитал как составляющую национального богатства дороже, чем овеществленную его часть. Стоимость населения Англии - в 417 млн. фунтов стерлингов, а вещественное богатство - в 250 млн. фунтов стерлингов. [3] «Эта парадоксальная идея глубже, чем может показаться на первый взгляд: Пети искал способ как-то оценить размеры личного элемента производительных сил - трудовых навыков, сноровки, потенциала развития техники». [4]

У. Петти заложил основы количественной оценки массовых общественных явлений, в частности, изменений в народонаселении, в своих «Опытах по политической арифметике» (работы 1681-1687г.г.). Впервые примененный им термин «политическая арифметика» в дальнейшем использовался для обозначения не только специфического метода исследования, но и характеристики самих текстов, в которых с помощью математических методов проводился анализ продолжительности жизни и смертности населения. Работы английских, голландских, французских и шведских ученых 18 века стали основой формирования демографии и статистических исследований 19 столетия. [5] У. Петти различает «бесполезные занятия» и те, которые «повышают квалификацию людей». [6] Он видит пользу в образовании и отмечает: 
«...школы и университеты должны быть организованы так, ... чтобы в качестве учеников могли быть избраны действительно способнейшие». [7]

Позднее теория человеческого капитала была развита в «Исследовании о природе и причинах богатства народов» А.Смита, 1776 г. издания. В этой связи отметим, прежде всего, текст III главы 2 книги работы Смита, посвященной анализу сущности производительного и непроизводительного труда [8] и текст X главы 1 книги, посвященной анализу условий дифференциации оплаты труда. [9] Смит формулирует ряд положений, взятых за основу в современной теории человеческого капитала. Так, оплата труда у Смита - величина, зависимая от «...легкости и дешевизны или трудности и дороговизны обучения данной профессии», а «...работа, которой он обучается, возместит ему, помимо и сверх обыкновенной заработной платы за обычный труд, все расходы на обучение, с обычной прибылью на капитал, равной суммы. И это должно быть осуществлено в приемлемый срок, принимая во внимание продолжительность человеческой жизни так же, как это делается при более определенном сроке у машины». [10] Смит утверждает, что расходы, связанные с вложениями в человека, способствуют росту производительности и оплаты его труда, и эти процессы могут быть сопоставимы с процессами воспроизводства основного капитала.

Важный вклад в развитие теории человеческого капитала внес Ж.Б. Сэй. Он доказывает, что профессиональные навыки и способности, приобретенные посредством затрат на воспитание и обучение, приводят к росту производительности труда, накапливаются, и в связи с этим могут рассматриваться как капитал. Ж.Б. Сэй в VII главе «Трактата по политической экономии» пишет: «Человек не рождается с теми способностями и силами, которые были бы достаточны для исполнения даже самой легкой работы. Эти способности и силы ... могут быть рассматриваемы как капитал... суммы, употребленные на воспитание рабочего, были ... потрачены производительно, потому что произвели человека, представляющего собой накопленный капитал». [11]

Джон Стюарт Милль в «Принципах политической экономии» 1848 года не признает самого человека как богатство, но убежден, что «... его приобретенные способности, которые ... порождены трудом, с полным основанием...попадают в эту категорию.... Мастерство, энергия и настойчивость рабочих страны в такой же мере считаются ее богатством, как и их инструменты и машины». [12]

Кульминации своего развития теория капитала достигает в работах К. Маркса, определяющего капитал как самовозрастающую стоимость, приносящую прибавочную стоимость в ходе эксплуатации наемного труда. Перенося акценты на сам факт эксплуатации наемного рабочего, К. Маркс отмечает: «...рабочая сила в руках рабочего является товаром, а не капиталом;... в качестве капитала она функционирует после продажи в руках капиталиста во время самого процесса производства». [13] Переменный капитал, (по Марксу - затраты на покупку рабочей силы) в процессе производства меняет свою величину. В «Экономических рукописях 1857-1859 гг.» Маркс приходит к выводу, что главным капиталом общества является сам человек. 
[14] К. Маркс указывает, что развитие физических, умственных и творческих созидательных сил человека - есть «действительное богатство», «главная производительная сила общества». [15]

Неоклассики продолжили исследование человеческого капитала. В 1890 году в «Принципах экономической науки» А.Маршалл вводит категорию «подвижный капитал», предвосхищая идею капитала как фонда ценности в целом. В IV главе 1 тома он отмечает: «Имеющиеся в распоряжении блага, выражающие определенную денежную стоимость, которые можно использовать для любых целей [курсив наш], часто называют «свободным» или «подвижным» капиталом». [16] В XI главе 3 тома «Принципов экономической науки» А.Маршалл раскрывает экономическую сущность процессов ценообразования и накопления человеческого капитала: «...имеется много общего между процентом на капитал и заработной платой...существует общая взаимосвязь между причинами, управляющими ценами предложения вещественного и личного капитала, мотивы, побуждающие человека накапливать личный капитал как вложения в образование его сына, схожи с теми, которым подчиняется накопление вещественного капитала для его сына». [17]

Глава школы Лозаннского университета Л. Вальрас в работе 1874 года «Элементы чистой политической экономии» пишет: «...люди - это естественные капиталы и ...они появляются вновь вследствие воспроизводства». [18] Л.Вальрас одним из первых в работе 1898 года «Этюды прикладной политической экономии» формулирует фундаментальное различие между запасами капитала и производимыми с их помощью потоками доходов. [19]

Как самостоятельный раздел экономического знания теория человеческого капитала вполне оформилась на рубеже 50-60-х годов 20 века. Заслуга ее выдвижения принадлежит известному американскому экономисту, лауреату Нобелевской премии Т.Шульцу, а базовая теоретическая модель («общая теория инвестиций в человеческий капитал») была разработана в книге Нобелевского лауреата Г.Беккера «Человеческий капитал: теоретический и эмпирический анализ» (1964). Эта работа признана классикой современной экономической мысли.

Человеческий капитал, по Беккеру, это имеющийся у каждого индивида запас знаний, навыков, мотиваций. В основу анализа Г.Беккер положил представление о поведении человека, как рациональном, учитывающем имеющуюся информацию, например, о соотношении величины заработной платы и возраста, о зависимости нормы безработицы и уровня образования. По мнению Г.Беккера существует ряд «эмпирических феноменов», сопровождающих «инвестиции в человеческий капитал». Под такими инвестициями им понимаются вложения в улучшение квалификации, в знания, в здоровье, которые способствуют увеличению денежных или натуральных доходов. Он исследует влияние на величину человеческого капитала формального образования, общей и специальной подготовки, подготовки на рабочем месте, улучшения физического и эмоционального состояния человека. Замечательное свойство данного исследования в том, что Г.Беккер формализует обнаруженные им закономерности, используя предельный анализ. [20] Сформулированная им концепция стала основой для всех последующих исследований в этой области. 
Большой вклад в обоснование первоочередности институциональных изменений в развитии человеческого капитала внес Т. Шульц. [21] Его монографии «Преобразуя традиционное сельское хозяйство» (1964), «Инвестиции в человеческий капитал: роль образования и научных исследований» (1971), «Инвестиции в людей: экономика качества населения» (1981) получили мировое признание. Под институтами, влияющими на человеческий капитал, Т. Шульц понимает правила поведения: кредитно-денежные отношения, организационные структуры, основанные на контрактах, кооперации, трудовое законодательство. Т. Шульц первым стал применять к человеческому капиталу те же категории, с помощью которых классики исследовали капитал в обычном смысле: прибыль, условия инвестирования и т. д. Инвестирование в человеческий капитал для Шульца - путь преодоления бедности. Особенное внимание в проведенном анализе уделяется расходам на образование и оценке стоимости рабочей силы, включая расходы на образование. Важную роль Т. Шульц отводит высшему образованию молодежи, считая «тремя главными функциями высшего образования» обнаружение таланта, обучение и научную работу.

Современная экономическая теория использует знание, накопленное в ходе исследования сущности человеческого капитала. Общепринято понимание человеческого капитала как оценки «...воплощенной в индивидууме потенциальной способности приносить доход. Человеческий капитал включает врожденные способности и таланты, а также образование и приобретенную квалификацию». [22] А так же понимание того, что формирование человеческого капитала, подобно накоплению физического или финансового капитала, требует отвлечения средств от текущего потребления ради получения дополнительных доходов в будущем. К важнейшими видами человеческих инвестиций относят рождение и воспитание детей, образование, подготовку на производстве, миграцию, информационный поиск.

В толковом экономическом словаре мы находим важные характеристики рассматриваемой сущности, такие как: наличие маржинальных закономерностей в ее функционировании, а именно появление «дополнительной производительности людей с опытом и квалификацией»; наличие принципиально различных источников формирования человеческого капитала: «Человеческий капитал может быть приобретен путем специальной подготовки или вследствие обучения на производстве... Издержки по созданию человеческого капитала ложатся в основном на самих людей, их семьи, благотворительные учреждения или государство»; и присутствие такой особенности как моральный износ: «Подобно капиталу в форме материальных активов, он подвержен старению в результате изменения технологии или спроса». [23]

Оценка человеческого капитала современной экономической наукой проводится с двух позиций: человеческий капитал как запас и как поток доходов. «Человеческий капитал как запас имеющийся у человека запас здоровья, знаний, навыков, способностей, мотиваций, которые содействуют росту его производительности труда и влияют на рост доходов». [24] При такой оценке в структуре человеческого капитала выделяют: природные способности; общую культуру; общие и специальные знания; приобретенные способности, знания, опыт; умение применять полученные знания в нужный момент в нужном месте. Понимание человеческого капитала как 
потока доходов означает, что вложения в человеческий капитал становятся важным активом, обеспечивающим более высокий поток доходов на протяжении всей жизни человека. Главным стимулом стремительного роста вложений в человеческий капитал является ожидание высокого дохода.

По мнению исследователей, ряд положений теории человеческого капитала для белорусской экономики в целом применимы, но нуждаются в уточнении. Во-первых, в белорусской экономике наблюдается значительная деформация принципа оплаты труда. Несмотря на то, что статистические данные демонстрируют наличие положительной зависимости заработков человека от уровня его образования, эта зависимость не носит характера постоянно наблюдаемой закономерности: не всегда более высокий уровень образования ведет к более высоким доходам. Данная связь рассматривается для экономики Беларуси как нарушаемая тенденция. Например, в январе 2014 г. в промышленности средняя заработная плата составила 5903,9 тыс. рублей, в образовании - 3 657,7 тыс., в том числе профессорско-преподавательского состава - 5 985,3 тыс. рублей. Средняя заработная плата врачей составила 6 164,7 тыс. рублей. [25] При этом «число работников с высшим образованием в общем количестве работающих составляет в области ... науки и научного обслуживания - около 65 процентов, образования - свыше 50 процентов, промышленности и строительства - по 18,5 процента». [26] Заработная плата врачей и преподавателей вузов, имеющих обязательно высшее образование, часто - научные степени, сопоставима с оплатой труда в промышленности и строительстве, где только 18,5\% персонала имеют высшее образование. Наибольшая деформация принципа оплаты труда наблюдается в областях занятости, требующих самой высокой квалификации.

Уровень средней заработной платы в отрасли зависит от разных факторов (величина предложение труда, уровень производительности труда, финансовые показатели деятельности и т.д.), однако, «приоритеты ранжирования [А.Б. - отраслей по величине оплаты труда] должны иметь направленность: отраслям с большей долей высококвалифицированной рабочей силы соответствует более высокий уровень средней заработной платы». [27] Уточнение в наше понимание того, существует ли указанная зависимость в современной мировой практике, вносят исследования, проведенные во многих странах (развитых и развивающихся): указанная тенденция представляет собой одну из основных закономерностей развития национальных экономик и отражает наличие устойчивой положительной зависимости доходов человека, фирмы, государства от уровня образования человека. [28] Немецкая компания SAP AG (чистая прибыль €3,438 млрд (2011г.); 54 тыс сотрудников (2012г.) - производитель программного обеспечения, приводит данные, согласно которым «дополнительное образование [А.Б. - в данной компании] означает прибавку к зарплате...труд специалистов с дипломом магистра ценится на 18\% выше труда выпускников средних школ. Докторская степень заметно повышает зарплату: она становится на 53\% больше, чем у сотрудников без профильного образования». [29] Между уровнем образования и уровнем развития и доходом национальных экономик есть тесная связь. «Человеческие ресурсы в Гонконге дают $88 \%$, а в Сингапуре - 85\% всего совокупного дохода. США - мировой лидер по 
прибыли, получаемый от использования человеческих ресурсов (доходы от них составляют 62 трлн 197 млрд долларов), Япония занимает второе место (40 трлн.345 млрд. долл.), Китай на третьем месте (23 трлн. 343 млрд. долл.), а Германия с населением меньше Китая в 15 раз имеет почти ту же сумму от вовлечения человеческих ресурсов (22 трлн. 652 млрд. долл.) Главное, чем определяется отдача от человеческих ресурсов - это уровень образования». [30]

Во-вторых, в теории человеческого капитала содержится положение о том, что продолжительность образовательного процесса должна находить отражение в качестве навыков и умений, приобретаемых в ходе его. В современных условиях это положение находится в контексте идеи о перманентности образования. Действительность указывает на смену приоритетов официального обучения и самообучения в ходе практической деятельности. Во многих отраслях белорусской экономики большую значимость приобретает «доподготовка» специалиста по месту работы, учитывая скорость смены технологических процессов.

Самообразование, самостоятельное получение знаний и опыта выходит на передний план. ИКТ способствуют полномасштабному разворачиванию указанных тенденция и процессов, поскольку являются способом, позволяющим в сокращенном временном режиме, относительно дешево, доступно организовать накопление человеческого капитала. Получает широкое распространение не только получение отдельных элементов знания в определенных областях, но и системного образования через дистанционную форму обучения.

Самообучение, если оно повышает производительность труда и позволяет получать большую заработную плату в данной фирме, обозначается авторами теории человеческого капитала как специальная подготовка, если же самообучение позволяет повысить производительность в случае занятости работника и в других фирмах, то оно признается общей подготовкой. И в том, и в другом случае лица, получающие дополнительное образование, дополнительные навыки, согласны платить за это, планируя рост оплаты труда в будущем периоде. Фирма же, оплачивает она этот процесс или нет, извлекает из «доподготовки» работника выгоду, и тем большую, чем в большей степени оплата самообразования перекладывается на плечи работника. Способность к самообучению расценивается работодателями как явное преимущество, поскольку позволяет недорого или вовсе за счет наемного работника адаптировать качества рабочей силы к имеющейся технологии.

Нетрудно предположить, что, чем большую квалификацию имеют наемные работники, тем больше они имеют навыков к самообразованию, и даже тяготеют в силу специфики своей трудовой деятельности к самообучению. Тем большую потенциальную и реальную выгоду извлекают их работодатели. Однако, если в оплате труда нивелируется, не находит отражение этот внутренний потенциал к росту компетенций, то и не обнаруживается потенциально возможный рост производительности труда (через поиск рационализации производственных процессов, через инновации и т.п.). На поверхности это выглядит как индифферентность к нововведениям, имея скрытую сущность. Это происходит потому, что те ресурсы, которые получает работник в качестве заработной платы, недостаточны для воспроизводства высококвалифицированной 
рабочей силы. Их достаточно только на «кормление семьи» работника. Попытка отвлечь ресурсы, необходимые для восстановления сил и сохранения здоровья работника на получение дополнительных навыков, дополнительное обучение, будь оно общим или специальным, приводит к ранней смерти физического тела как носителя интеллекта. В условиях белорусской экономики сохраняется тенденция роста числа смертей в молодом возрасте, при росте числа обучающихся и росте продолжительности обучения. Последнее, казалось бы, должно уменьшить, по крайней мере, число смертей от тяжелых инфекционных заболеваний и смертей от внешних причин. Но этого не происходит, в том числе и потому, что у домохозяйств отсутствуют средства на профилактику заболеваний, в том числе психосоматических расстройств. Наступление смерти молодого человека в трудоспособном возрасте означает для национального хозяйства растрату стоимости, а не ее авансирование, как предполагается, когда финансируется рождение, воспитание, обучение работника.

Таким образом, если фирма не оплачивает дополнительное обучение, необходимое для адаптации работника к новым технология, она экономит, получает дополнительные выгоды. Национальное же хозяйство проигрывает, в его рамках провоцируются перераспределительные тенденции не в пользу носителей компетенций. На практике это выглядит так, что руководство, особенно государственных фирм, понимая, что «горстка» специалистов занимается самообразованием в любом случае, финансируется это работодателем или нет, может продолжать нерационально расходовать «высвободившиеся» ресурсы.

В-третьих, теория человеческого капитала содержит положение, согласно которому имеется положительная связь между полученным образованием и возможностью трудоустройства. Исследования экономической активности населения Европейского Союза (Европы-27), по возрасту и уровню образования показывают, что «уровень экономической активности прямо зависит от уровня образования: чем выше образование, тем выше и экономическая активность населения всех основных групп рабочих возрастов. Уровень безработицы связан с уровнем образования обратной зависимостью». [31] В Беларуси структура безработицы по уровню образования имеет те же особенности. Из числа безработных в 2013 году не более 11,14\% имеют высшее образование, 35,2\% - общее среднее образование. [32]

Факт преобладания занятости в сфере услуг постиндустриальных экономик (до 70-80\% всех занятых работают в сфере услуг) несколько «искажает» указанную тенденцию, т.к. на первый план выходят характеристики, не связанные с уровнем образования. Это могут быть такие факторы, как семейное положение, возраст, и даже внешние данные. Данные тенденции - не исключение для трансформационных экономик, в частности - белорусской. Однако тот факт, что в сфере услуг белорусской экономики по итогам 2012 г. занято только 44,5 \% от общего числа занятых, говорит о том, что указанные факторы имеют меньшее влияние, т.е. в меньшей степени способны исказить положительную зависимость полученного образования и занятости. [33]

Из перечисленных «эмпирических феноменов», нашедших отражение в теории человеческого капитала и возможных к адаптации применительно к условиям Беларуси, самое 
актуальное, на наш взгляд, - явление связи между уровнями доходов и образования. Эта связь отражается в показателе нормы отдачи от инвестиций в человеческий капитал, в частном случае в образование. Норма отдачи от инвестиций в человеческий капитал выступает как специфический вид нормы прибыли и заслуживает глубокого, всестороннего исследования как показатель эффективности капитализации стоимости. Одно из последних исследований такого рода - работа А. Чубрика и Г. Шимановича «Отдача на образование и оценка человеческого капитала в Беларуси». [34] Методика подсчета нормы окупаемости инвестиций в человеческий капитал аналогична анализу окупаемости физического капитала. А именно: соотносятся дополнительные издержки, связанные с получением образования, профессиональным обучением, здравоохранением, с дополнительными выгодами, получаемыми после совершения указанных затрат. Это хорошо известный анализ предельных величин, требующий формулирования принципа оптимизации.

Определение норм отдачи от инвестиций в образование может быть осуществлено на разных уровнях - от домохозяйств до национальных экономик. Полученное знание позволит домохозяйствам и правительствам рационализировать финансирование образовательных услуг. Норма отдачи инвестиций в образование выступает «индикатором производительности образования и значительным стимулом для индивидов инвестировать в собственный человеческий капитал». [35]

\section{ВЫВОДЫ}

Теория человеческого капитала является теоретической и практической методологией решения проблем экономического роста и демографического развития, особо - в части выработки рекомендаций по проведению конкретных мер демографической политики. Практическое значение имеет анализ действий членов домохозяйств и семей в целом. А именно: причинности того или иного выбора в планировании деторождения (воспроизводстве рабочих сил), в занятости женщин детородного возраста в форме найма (или предпочтение занятости женщин как домохозяек), в получении образования родителями и детьми (выбор формы, продолжительности, качества образования), в перераспределении богатства между поколениями (отчуждение богатства родителей в пользу увеличения человеческого капитала детей). Отдельного исследования заслуживает возрастающая роль женщины-матери в воспроизводстве поколений и принимаемые женщинами решения по деторождению, занятости в общественном производстве, получению образования и желаемой величины дохода, участию в государственном управлении и т. д.

Проведение политики стимулирования экономического роста невозможно без решения проблем демографии, иначе все эти меры лишаются стратегической цели, главной цели правительства - «сбережения населения», по образному выражению А.И. Солженицина. Приоритетный объект инвестиций в человеческий капитал Беларуси на данном этапе инвестиции в деторождение. Результаты выполнения программ демографической безопасности свидетельствуют о росте рождаемости, но меньшими темпами, чем темпы роста смертности. Для 
положительного естественного прироста населения страны необходимы инвестиции не только в деторождение, но и в профилактическую медицину. В развитых в экономическом отношении странах такие инвестиции составляют до 40\% инвестиций в здравоохранение. Сохранение здоровья нации для сохранения населения - главный приоритет современного этапа. Особо ценным в этой связи является создание доказательной базы величины ущерба экономике вследствие преждевременной смерти или потери трудоспособности, когда не компенсируются затраты общества на формирование человеческого капитала.

Особого исследования заслуживают условия инвестирования в человеческий капитал в современной экономике, а так же наличие искажающих основную тенденцию явлений деформации принципа оплаты труда, перекладывания финансирования самоподготовки на работника, низкие нормы отдачи от инвестиций в человеческий капитал.

Если, как и авторы теории человеческого капитала, оценивать индивида как рационально действующего субъекта, понимающего положительную взаимосвязь инвестиций в человеческий капитал с доходом и занятостью, и допустить, что эта взаимосвязь - объективная тенденция, которая может использоваться для обогащения нации, то следует взять эту зависимость за основу для построения системы мер демографической политики - таких, которые имеют высокую степень управляемости, поскольку задействуют механизмы личной мотивации. Инвестирование в человеческий капитал - не только путь преодоления бедности для отдельного индивида, но и направление экономического развития для национальной экономики.

Теория человеческого капитала притягивает исследователей, поскольку несет в себе знание общих закономерностей и характеристик развития важнейшей составляющей национального богатства. В ней нет готовых рецептов обогащения нации, но она определяет пути поиска его. Следует лишь учитывать особенности современного этапа развития национальных экономических систем.

\section{ЛИТЕРАТУРА}

1. Нуреев, Р.М. Экономика развития: модели становления и модернизации рыночной экономики / Р.М. Нуреев. - М: Норма, 2008- 367с. - С. 130.

2. Нуреев, Р.М. Экономика развития: модели становления и модернизации рыночной экономики / Р.М. Нуреев. - М: Норма, 2008- 367с. - С. 130.

3. Петти, В. Экономические и статистические работы. Т. I и II / В. Петти - М.: Соцэкгиз, 1940 - 324 c.

4. Аникин, А.В. Юность науки; Жизнь и идеи мыслителей - экономистов до Маркса / А.В. Аникин. - М.: Политиздат, 1985. - 367 с. - С. 68-69.

5. Демографический энциклопедический словарь / под ред. Валентей Д.И - М.: Советская энциклопедия, 1985. - 340 с.

6. Петти, В. Экономические и статистические работы. Т. I и II / В. Петти - М.: Соцэкгиз, 1940 - 324 c. - C. 182. 
7. Петти, В. Экономические и статистические работы. Т. I и II / В. Петти - М.: Соцэкгиз, 1940 - 324 c. - C. 82.

8. Смит, А. Исследование о природе и причинах богатства народов (книги I - III) / А. Смит. - М.: Наука, 1992. - 572 с. - С. 467-469.

9. Смит, А. Исследование о природе и причинах богатства народов (книги I - III) / А. Смит. - М.: Наука, 1992. - 572 с. - С. 222-230.

10. Смит, А. Исследование о природе и причинах богатства народов (книги I - III) / А. Смит. - М.: Наука, 1992. - 572 с. - С. 224.

11. Сэй, Ж.Б. Трактат политической экономии. Пер. Е.Н. Каменецкой [Электронный ресурс] / Ж. Б. Сэй. — Режим доступа: http://www society.polbu.ru/say_politeconomy/ch00_i.html - Дата доступа: 22.02.14.

12. Миль, Дж. С. Основы политической экономии. Т.1 / Дж.С. Миль - М.: Прогресс, 1980 496 c. - C. 139.

13. Маркс, К Капитал // К. Маркс, Ф Энгельс. Соч. 2-е изд, т.23 - М.: Политиздат, 1960. 907 c. - C. 190.

14. Маркс, К.Экономические рукописи 1857-59 гг. // К. Маркс, Ф Энгельс. Соч. 2-е изд, т.46. - Ч.ІІ. - М.: Политиздат, 1968. - 559 с. - С. 221.

15. Маркс, К Капитал. Критика политической экономии // К. Маркс, Ф Энгельс. Соч. 2-е изд, Т.49 - М.: Политиздат, 1974. - 555c. - С. 182-183.

16. Маршалл, А.Принципы экономической науки. Т.1 / А. Маршалл - М.: Прогресс, 1993. 415 c. - C. $134-135$.

17. Маршалл, А.Принципы экономической науки. Т.3 / А. Маршалл - М.: Прогресс, 1993. 351 c. - C. 179.

18. Вальрас, Л. Элементы чистой политической экономии / Л.Вальрас - М.: Изограф, 2000. 448 c. - C. 155.

19. Вальрас, Л. Этюды прикладной политической экономии (Etudes d’èconomie politique appliquee) [Электронный pecypc] / Л. Вальрас - Режим доступа: http://dic.academic.ru/dic.nsf/ruwiki/831737- Дата доступа: 25.02.14.

20. Беккер, Г.С. Человеческое поведение: экономический подход / Г.С. Беккер - М.: ГУ ВШЭ, 2003. - 672 с. - С. 50-89.

21. Человеческий капитал: содержание и виды, оценка и стимулирование: монография / Смирнов В.Т., Сошников И.В., Романчин В.И., Скоблякова И.В.; под ред. В.Т. Смирнова. - М.: Машиностроение -1, Орел: Орел ГТУ, 2005. - 513с.

22. Экономический словарь [Электронный ресурс] / Режим доступа http:// mirslovarei.com/eco_a. - Дата доступа: 25.02.14.

23. Экономика. Толковый словарь / под ред. Осадчей И.М.. - М.: ИНФРА, Весь мир, 2000. $840 \mathrm{c}$. 
24. Нуреев, Р.М. Экономика развития: модели становления и модернизации рыночной экономики / Р.М. Нуреев. - М: Норма, 2008- 367с. - С. 130.

25. Официальный сайт Национального статистического комитета Республики Беларусь [Электронный ресурс]. - Режим доступа: http://belstat.gov.by/. - Дата доступа: 27.02.14.

26. Государственная программа развития высшего образования на 2011 - 2015 годы [Электронный ресурс]. - Режим доступа: http://www.pravo.levonevsky.org/bazaby11.ht/.../text171m. Дата доступа: 15.02.14.

27. Уголев, С.Н. Метод расчета зависимости динамики лрходов работников от уровня образования в Республике Беларусь / С.Н. Уголев, С.С. Дрозд // Вестник ГГТУ им. П.О. Сухого. 2003. - № 4. - C. 79-88. - С. 81.

28. Лавровская, О.Б. Социально значимые и прикладные направления исследований в области человеческого капитала в современной белорусской экономической науке [Электронный pecypc] / О.Б.Лавровская - Режим доступа: http://media.miu.by. - Дата доступа: 22.02.14.

29. Обзор зарплат специалистов SAP в 2012 году. [Электронный ресурс]. - Режим доступа: http:// www.sap.com/cis/. - Дата доступа: 30.02.14.

30. Иноземцева, Л.Н. Эффективность вложений в высшее образование: определение направления исследований [Электронный ресурс] / Л.Н.Иноземцева, Н.Д. Кликунов - Режим доступа: http://old.mebik.ru/pages/klikunov/articles/art/inozem.pdf.- Дата доступа: 10.02.14.

31. Демоскоп [Электронный ресурс]: электронная версия бюллетеня Население и общество. - 2008. - № 341 - 342. — Режим доступа: http:// demoscope.ru/weekly/2008/0341/barom04.php.- Дата доступа: 1.03.14.

32. Официальный сайт Министерства труда и социальной защиты [Электронный ресурс]: Режим доступа: http:// www.mintrud.gov.by. - Дата доступа: 1.03.14.

33. Официальный сайт Министерства труда и социальной защиты [Электронный ресурс]: Режим доступа: http:// www.mintrud.gov.by. - Дата доступа: 1.03.14.

34. Чубрик, А. Отдача на образование и оценка человеческого капитала в Беларуси [Электронный ресурс] / А. Чубрик, Г. Шиманович - Режим доступа: http://www.research.by. - Дата доступа: 20.02.14.

35. Лавровская, О.Б. Социально значимые и прикладные направления исследований в области человеческого капитала в современной белорусской экономической науке [Электронный pecypc] / О.Б.Лавровская - Режим доступа: http://media.miu.by. - Дата доступа: 22.02.14. 